\title{
ADOPTION OF MOBILE BANKING
}

\author{
Golan Carmi ${ }^{1}$ and Nethanel Jay Drezner ${ }^{2}$ \\ ${ }^{I}$ Information Systems Department \\ ${ }^{2}$ Industrial Engineering \& Management Department \\ Jerusalem College of Technology, Havaad Haleumi 21 Jerusalem, 91160, Israel
}

\begin{abstract}
The study examines which technical and psychological factors affect the willingness of the consumer to adopt a new financial application, as part of the transition to mobile banking. Six factors were examinee: relative advantage, complexity, compatibility, accessibility, trialability and perceived risk. To this end, a self-reported questionnaire was distributed via social media among 402 banking customers. Findings indicate that the four criteria with the significant impact on adoption of a financial application to smartphones are: relative advantage, compatibility, accessibility and trialability.
\end{abstract}

\section{KEYWORDS}

Financial Application, Smartphone Application, Application Adoption, Mobile Banking

\section{INTRODUCTION}

In recent decades the banking industry has undergone significant and revolutionary processes. The tools used by the customer for banking services have evolved and improved over time, due to technological changes: from services provided only by a traditional bank branch with clerks, through ATM operations and automated positions, telephone banking, online banking and financial applications. Nowadays, more and more transactions and acquisitions are controlled directly from mobile devices especially smartphones applications (Liu \& Li, 2010). It is important to define the main technological and psychological factors that affect the choice of potential customers to adopt or prefer financial applications.

Previous studies have examined the adoption of financial applications based on a single theory as a theoretical basis (Al-Gahtani, 2003; Chen, Gillenson, \& Sherrell, 2004; Koenig-Lewis, Palmer \& Moll, 2010; McCloskey, 2006; Ndubisi \& Sinti, 2006). In order to examine the phenomenon in a wider way, we used this study in two theories as a theoretical basis: DIT theory (Diffusion of Innovative Technology) suggested by Rogers (1983), and TAM model (Technology Acceptance Model) presented by Davis (1989). Finding the influence of the technological and psychological factors can help develop and implement future financial applications. Banks will be able to develop applications that truly meet the needs, desires and concerns of their target customers, thus able to save costs and improve their services to their customers.

\section{BODY OF PAPER}

The study involved 402 customers of the banks, when the questionnaire was distributed online by social media. An analysis of the questionnaires was found that $48 \%$ were men and $52 \%$ were women; most of the customers were married (68\%), $40 \%$ were of age 18-25 and $43 \%$ between ages 26-35; most of them were academics (61\% first degree and $20 \%$ second); about a third works in the high-tech and finance industries and the rest works in education, marketing, medicine, governmental and more; and $40 \%$ earn average wage in the economy and above.

Six independent variables were tested in this study: relative advantage, complexity, compatibility, accessibility, trialability and perceived risk. (1) Relative advantage: refers to the extent to which technological innovation is perceived as providing more advantages than its predecessor. A relative 
advantage results in increased efficiency, economic benefits, and improved status. The assumption is that when new technology is perceived to have a relative advantage or benefit there will be a tendency to adopt it. (2) Complexity: The extent to which we can relate to understanding and using technology. High complexity adversely affects the adoption of new technologies, and is the opposite of ease of use. Where ease of use refers to the extent to which a financial application is perceived as easy to understand and operate. The assumption is that the complexity of use is a major factor in the adoption of a financial application. (3) Compatibility: Refers to the extent to which the service is perceived as consistent with the values, beliefs, habits, and experiences of users. It is likely that there is a relationship between compatibility and adoption of a financial application. (4) Accessibility: The ability to access banking services at any time and in any place without waiting time or delay, without being dependent on the opening hours of banking branches and carrying out financial transactions immediately. It is assumed that advanced access to banking services over its advantages, especially availability, convenience and velocity will affect application adoption. (5) Trialability: Refers to the possibility of experimenting with new technology before adoption. It is assumed that users who are given the opportunity to try new technology will express less concern and feel more comfortable adopting the technology. (6) Perceived risk: This feature relates to the risk of using innovative technology. The risk perception is due to insufficient knowledge of the technology and the expected results from its use. In the context of banking services on the mobile phone, the risk perception is related to privacy and information security problems, such as: loss or theft of passwords or mobile devices, hacking into a mobile phone, leakage of financial information. The assumption is that there is a relationship between perceived risk and adoption of financial applications.

The main findings showed that four out of six variables: relative advantage, compatibility, accessibility and trialability - have significant positive effect on financial application adoption. The statistical analysis shows that, the higher the application's relative advantage, the adoption of financial application was more extensive; the higher the application compatibility, the adoption of a financial application was more widespread; as application accessibility was higher, there was widespread adoption of the mobile application; the more the customer has trialability the application, the more widespread adoption of the financial application. For variables, complexity and perceived risk, statistical significance was not found. In terms of demographic findings' it was found a significant negative correlation between age and relative advantage, so that as the age of the user increased the relative advantage decreased. A significant positive correlation was found also between age and accessibility, so that as the age of the user increased the accessibility decreased. No significant correlation was found between age and compatibility, complexity, trialability and perceived risk. In addition, it was found a significant negative correlation between age and the willingness to adopt a financial application, so that as the age of the subject increases the adoption willingness decreases. As for the other demographic variables: gender, family status, level of education, field of work and level of income - no significant correlation was found on adoption financial application.

\section{CONCLUSION}

The main conclusion of the study is that the four criteria with the significant effect on the adoption of financial application are relative advantage, compatibility, accessibility and trialability. Therefore, banks need to focus their development and marketing efforts on emphasizing the advantage and benefit of financial uses of the application over more familiar banking methods such as the Bank's website or face-to-face service at the bank's counter. Also, developers should ensure that the use of the financial application is as appropriate as possible for the use of the customers, that the interface is intuitive and fast-learning, especially for users who have been accustomed to performing operations on the banks' websites.

In addition, ensure that the services in the application are as accessible as possible and make sure that the application works $24 / 7$ without any country or region restrictions. Periods of service unavailability or long waiting times when implementing an application will likely have a significant influence on customer usage. Moreover, enable customers experiment with the application to lessen concerns about using it, as well as offer a limited free option in addition to a unlimited paid option. Finally, the banks should take into account the age of the customers, as a parameter that particularly affects the adoption of a financial application on the smartphone, to conduct instruction in using the financial application as the customer age is higher. 
We recommend programmers to focus on meeting the customers' needs that best match the criteria delineated above. By understanding the influencing factors, marketers should use these criteria to reduce the psychological concerns of customers that delay the adoption of a financial application. Since financial applications are becoming more useful as financial transfers, other behavioral aspects that influence the adoption of technology should be examined. We recommend conducting further research based on behavioral, economic and technological theories. A better understanding of the influencing factors will derive a better planning and development of financial applications, regarding the most significant factors: relative advantage, compatibility, accessibility and trialability. This process will result better and wider adoption of financial applications by customers, and will bring more customers to do banking operations and use financial transfers by smartphones.

Future studies can use other theoretical basis for research; to examine specific populations, for example, in terms of the third age or religious populations; and to examine cultural and social influences factors on the adoption of financial applications.

\section{REFERENCES}

Al-Gahtani, S. S. (2003). Computer technology adoption in Saudi Arabia: Correlates of perceived innovation attributes. Information Technology for Development, 10(1), 57-69.

Chen, L., Gillenson, M. and Sherrell, D. (2004). Consumer acceptance of virtual stores: A Theoretical Model and Critical Success Factors for Virtual Stores. ACM SIGMIS Database.

Davis, F. D. (1989). Perceived usefulness, perceived ease of use, and user acceptance of information technology. MIS Quarterly.

Liu, Y. and Li, H. (2010). Mobile internet diffusion in China: an empirical study. Industrial Management \& Data Systems 110 (3), 309-324.

McCloskey, D. W. (2006). The importance of ease of use, usefulness, and trust to online consumers: An examination of the technology acceptance model with older consumers. Journal of Organizational and End User Computing.

Ndubisi, N. O. and Q. Sinti (2006). Consumer attitudes, system's characteristics and internet banking adoption in Malaysia, Management Research News.

Koenig-Lewis, N., Palmer, A. and Moll, A. (2010). Predicting young consumers' take up of mobile banking services. International Journal of Bank Marketing.

Rogers, E. M. (1983). Diffusion of innovations (3rd). New York: The Free Press. 